\title{
Refractivity biases in GNSS occultation data
}

\author{
Georg Beyerle ${ }^{1}$, Stefan Heise ${ }^{1}$, Julia Kaschenz ${ }^{1}$, Gert König-Langlo ${ }^{2}$, \\ Christoph Reigber ${ }^{1}$, Torsten Schmidt ${ }^{1}$, and Jens Wickert ${ }^{1}$ \\ 1 GeoForschungsZentrum Potsdam, Dept. 1, Geodesy and Remote Sensing, \\ Potsdam, Germany gbeyerle@gfz-potsdam.de \\ 2 Alfred Wegener Institute for Polar and Marine Research, Bremerhaven, \\ Germany gkoenig@awi-bremerhaven.de
}

Summary. An analysis of atmospheric refractivity profiles observed by the geo-research satellite CHAMP between May 2001 and October 2004 reveals a negative bias compared to ECMWF meteorological fields at altitudes below $5 \mathrm{~km}$. In order to separate bias contributions caused by critical refraction from contributions induced by the receiver tracking process a comprehensive end-to-end simulation study was performed. The simulations are based on radio sonde profiles obtained aboard research vessel "POLARSTERN". Within a subset of 3039 profiles recorded on the Atlantic ocean between $60^{\circ} \mathrm{N}$ and $60^{\circ} \mathrm{S}, 1202$ profiles $(39.6 \%)$ are found with vertical refractivity gradients below the threshold value of $-157 \mathrm{~km}^{-1}$. Critical refraction layers occur mainly between 1 to $2.5 \mathrm{~km}$ altitude, above $3 \mathrm{~km}$ the occurrence of critical refraction can be disregarded. End-to-end simulations using these 3039 refractivity profiles confirm that four quadrant carrier phase extraction outperforms the two quadrant method currently implemented on CHAMP. Within regions of low signal-to-noise ratios 'open-loop' tracking methods yield improvements with respect to the current 'fly-wheeling' method.

\section{Introduction}

Atmospheric sounding by means of Global Positioning System (GPS) radio occultation (RO) may contribute to improvements in numerical weather prediction and climate change studies. Validation studies of past and current RO satellite missions, however, indicate systematic deviations between retrieved refractivities and corresponding data from meteorological analyses in the lower troposphere at tropical latitudes. These biases have been identified and discussed already in the GPS/MET validation study (Rocken et al, 1997). Similar biases are observed in the CHAMP data set (Wickert et al, 2004; Marquardt et al, 2003; Ao et al, 2003a; Hajj et al, 2004).

The CHAMP geo-research satellite (Reigber et al, 2004) was launched on 15 July 2000 and collects atmospheric occultation profiles since 11 Febru- 
ary 2001. As of 31 October 2004 the "BlackJack" occultation receiver aboard CHAMP has recorded 270,573 occultation events since activation of the operational occultation mode on 14 May 2001; $63.5 \%$ of these events pass the quality control criteria and are processed to profiles of atmospheric refractivity (Wickert et al, 2001, 2004; Hajj et al, 2004). For more detailed accounts of the RO methodology see e.g. Melbourne et al (1994); Kursinski et al (1997); Hajj et al (2002).

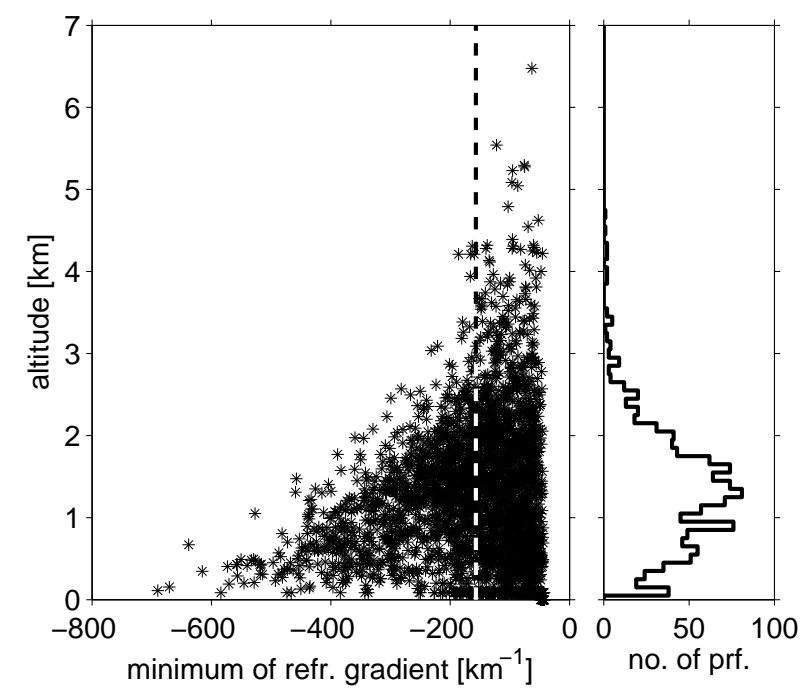

Fig. 1. Left: relationship between minimum vertical refractivity gradients and the corresponding altitudes derived from 3039 radio sonde observations. The dashed line marks the threshold value for critical refraction at $-157 \mathrm{~km}^{-1}$. Right: histogram distribution of the highest altitude at which critical refraction is observed.

\section{Data analysis and discussion}

\subsection{Radio sonde observations}

For more than 20 years Alfred Wegener Institute for Polar and Marine Research (AWI) performs aerological soundings of atmospheric temperature and humidity aboard research vessel "POLARSTERN" using Vaisala RS80 sondes (Vaisala, 1989). As of 28 August 2004 the data archive operated by AWI contains 23,676 measurements starting on 29 December 1982. Critical refraction in the lower troposphere induced by vertical gradients of the water vapour distribution occurs predominately at low and mid latitudes. Thus, we focus on a subset of 3039 profiles collected between $60^{\circ} \mathrm{S}$ and $60^{\circ} \mathrm{N}$. 
In Fig. 1 (left panel) the correlation between minimum vertical refractivity gradient and its altitude is plotted; $39.6 \%$ of the observed profiles exhibit critical refraction with vertical gradients below $-157 \mathrm{~km}^{-1}$ (dashed line). The right panel shows the histogram distribution of altitudes with critical refraction. Thus, critical refraction is a frequent phenomenon, at least in the marine environment, but it is restricted to altitudes below $2.5-3 \mathrm{~km}$.

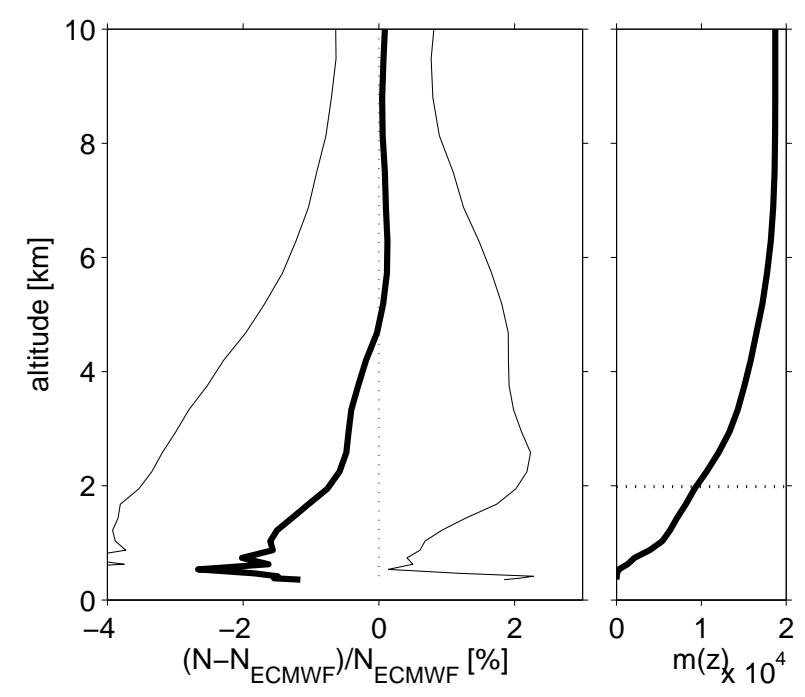

Fig. 2. Left: mean fractional refractivity deviation between CHAMP and ECMWF analyses restricted to the subset of 18,755 observations between $60^{\circ} \mathrm{S}-60^{\circ} \mathrm{N}$ and $45^{\circ} \mathrm{W}-15^{\circ} \mathrm{E}$ (thick line) and its one-sigma standard deviations (thin lines). Right: number of observed refractivity data as a function of altitude.

\subsection{CHAMP occultation data}

As of 31 October 2004 (day of year 305) 270,573 radio occultation events are collected by the occultation experiment aboard CHAMP. A fraction of $63.5 \%$ (171,942 observations) pass the quality control criteria of the operational processing software (Wickert et al, 2004) and are converted to vertical profiles of atmospheric refractivity. Version 5 of GFZ's occultation processing software (POCS) utilizes the Full Spectrum Inversion (FSI) method (Jensen et al, 2003) to obtain bending angle profiles in the troposphere. For details see Wickert et al (2001, 2004).

The retrieved CHAMP refractivity profiles are intercompared with meteorological analysis results provided by the European Centre for Medium-Range Weather Forecasts (ECMWF). ECMWF pressure and temperature values are calculated by linear interpolation between grid points $\left(0.5^{\circ} \times 0.5^{\circ}\right.$ resolution $)$. 
Linear interpolation in time is performed between $6 \mathrm{~h}$ ECMWF analyses fields. The comparison between RO observation and ECMWF is performed on the 60 pressure levels provided by the ECMWF atmospheric model ranging from the ground surface up to $0.1 \mathrm{hPa}$ (about $60 \mathrm{~km}$ altitude). Within the altitude range relevant for this study vertical spacing of the model grid points increases from about $200 \mathrm{~m}$ at $1 \mathrm{~km}$ altitude to about $700 \mathrm{~m}$ at $10 \mathrm{~km}$ altitude.

The mean fractional refractivity error and its standard deviation is shown in Fig. 2 (left panel) for a subset of 18,755 profiles observed within the region of $60^{\circ} \mathrm{N}-60^{\circ} \mathrm{N}$ and $45^{\circ} \mathrm{W}-15^{\circ} \mathrm{W}$. In the right panel the number of retrieved data points is plotted; only $50 \%$ of the profiles reach below an altitude of $z_{50 \%}=1.98 \mathrm{~km}$.

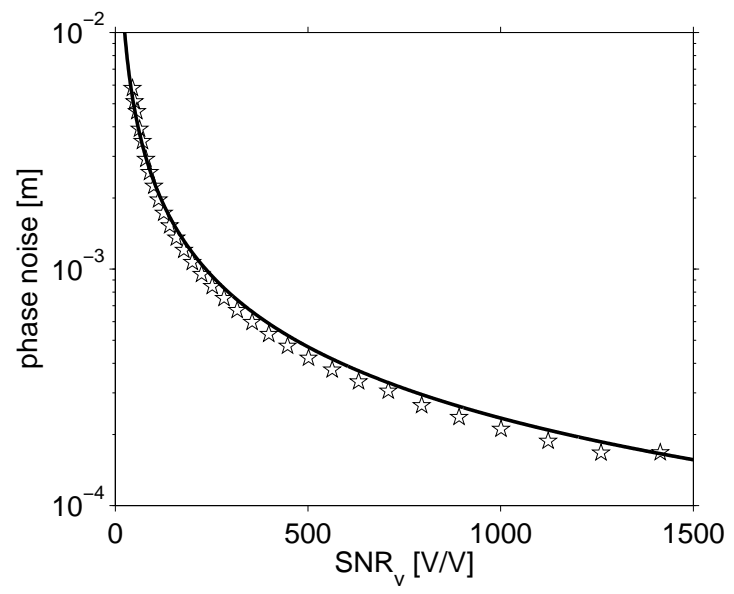

Fig. 3. Carrier phase noise $\sigma_{P L L}$ extracted from 31 simulated profiles with voltage $S N R_{v}$ between $44 \mathrm{~V} / \mathrm{V}$ and $1414 \mathrm{~V} / \mathrm{V}$ (stars). The full line marks the phase noise calculated from Eqn. 1.

\subsection{Simulation results}

The objective of the simulations is to separate receiver-induced bias contributions from those caused by critical refraction. For efficiency the simulation methodology described in Beyerle et al (2003) has been modified following Ao et al (2003b). From the sonde refractivity profile GPS carrier phase and amplitude data are modelled using the inverse FSI (Gorbunov and Lauritsen, 2004). The simulated data are tracked with software receivers producing amplitude and phase data. Finally, bending angles are calculated with the FSI method (Jensen et al, 2003) and refractivity profiles are obtained. We consider three receiver models: first, the ideal receiver exactly reproduces the input data; second, a 'fly-wheeling' receiver (Hajj et al, 2004) with two quadrant carrier 
phase extraction (Beyerle et al, 2003); and, third, an 'open-loop' receiver using four quadrant extraction (Sokolovskiy, 2001). In open-loop tracking the model is taken to be the ensemble average over 3039 Doppler profiles calculated from the data set of sonde observations.

To validate the implementation of the signal tracking process we compare the carrier phase-locked loop thermal noise $\sigma_{P L L}$ with the theoretically predicted value for a given voltage signal-to-nose ratio $S N R_{v}$ (Ward, 1996)

$$
\sigma_{P L L}=\frac{\lambda}{2 \pi} \sqrt{\frac{2 B_{w} 1 \mathrm{~s}}{\left(S N R_{v}\right)^{2}}\left(1+\frac{1 \mathrm{~s}}{\left(S N R_{v}\right)^{2} T}\right)}
$$

with carrier wavelength $\lambda$, sampling time $T$ and carrier loop bandwidth $B_{w}$. Setting $T=20 \mathrm{~ms}$ and $B_{w}=30 \mathrm{~Hz}$ the calculated phase noise is in approximate agreement with the corresponding values extracted from simulation results for $S N R_{v}$ values between $44 \mathrm{~V} / \mathrm{V}$ and $1414 \mathrm{~V} / \mathrm{V}$ (corresponding to carrier-to-noise density ratios between 30 and $60 \mathrm{~dB} \mathrm{~Hz}$ ) as shown in Fig. 3.
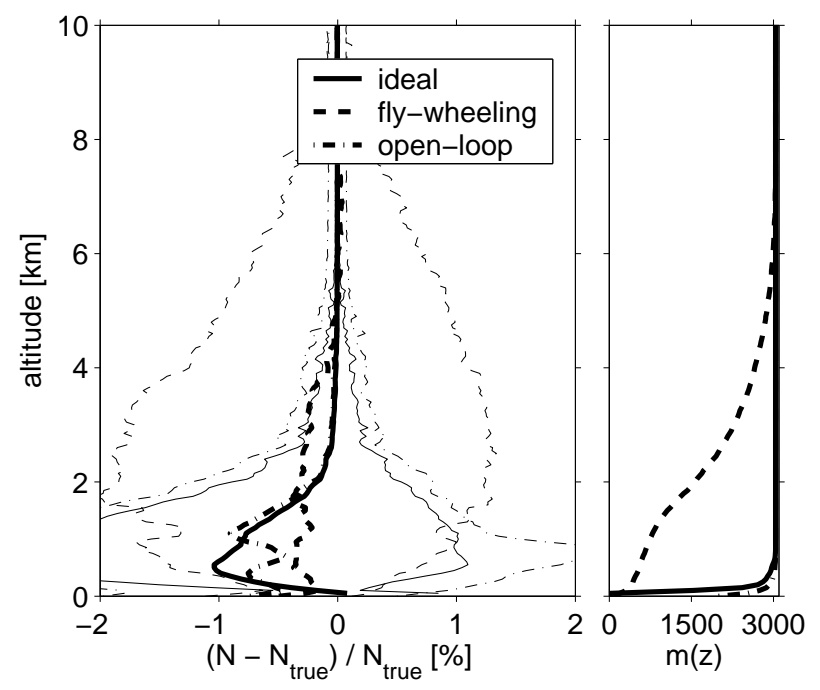

Fig. 4. Simulation results for three receiver models. The mean fractional refractivity error (left, thick lines), the corresponding standard deviations (thin lines) and the number of retrieved data points (right) are shown.

Fig. 4 presents the retrieval error in terms of the fractional refractivity deviation between retrieved and true refractivity for the three receiver models. Critical refraction causes a negative bias of up to $-1 \%$ within the planetary boundary layer (full line). About $-0.3 \%$ bias above $2.5 \mathrm{~km}$ in the 'fly-wheeling' profiles is attributed to receiver-induced signal tracking errors. 'Open-loop' 
tracking (dashed-dotted lines) performs better than 'fly-wheeling' in this altitude region and almost reproduces the ideal receiver profile (dashed-dotted vs. full lines).

\section{Conclusions}

An statistical analysis of 3039 radio sonde observations above the Atlantic ocean suggests that critical refraction is a frequent phenomenon in the lower troposphere; it is, however, restricted to altitudes below $2.5-3 \mathrm{~km}$. CHAMP occultation profiles exhibit a negative bias at altitudes up to $5 \mathrm{~km}$. On average, only $50 \%$ of the profiles reach below $2 \mathrm{~km}$ altitude at mid and low latitudes. Simulation studies reproduce on a qualitative level the tracking behavior of the CHAMP occultation receiver and suggest a significant improvement by implementing advanced 'open-loop' tracking schemes.

\section{References}

Ao CO, GAHajj, Meehan TK, Leroy SS, Kursinski ER, de la Torre Juárez M, Iijima BA, Mannucci AJ (2003a) Backpropagation processing of GPS radio occultation data. In: Reigber C, Lühr H, Schwintzer P (eds) First CHAMP mission results for gravity, magnetic and atmospheric studies, Springer, Berlin, pp 415-422

Ao CO, Meehan TK, Hajj GA, Mannucci AJ, Beyerle G (2003b) Lowertroposphere refractivity bias in GPS occultation retrievals. J Geophys Res 108(D18):4577, DOI 10.1029/2002JD003216

Beyerle G, Gorbunov ME, Ao CO (2003) Simulation studies of GPS radio occultation measurements. Radio Sci 38(5):1084, DOI 10.1029/2002RS002800

Gorbunov ME, Lauritsen KB (2004) Analysis of wave fields by Fourier integral operators and their application for radio occultations. Radio Sci 39:RS4010, DOI 10.1029/2003RS002971

Hajj GA, Kursinski ER, Romans LJ, Bertiger WI, Leroy SS (2002) A technical description of atmospheric sounding by GPS occultation. J Atmos SolarTerr Phys 64(4):451-469

Hajj GA, Ao CO, Iijima BA, Kuang D, Kursinski ER, Mannucci AJ, Meehan TK, Romans LJ, de la Torre Juarez M, Yunck TP (2004) CHAMP and SAC-C atmospheric occultation results and intercomparisons. J Geophys Res 109:D06109, DOI 10.1029/2003JD003909

Jensen AS, Lohmann M, Benzon HH, Nielsen A (2003) Full spectrum inversion of radio occultation signals. Radio Sci 38(3):1040, DOI 10.1029/2002RS002763

Kursinski ER, Hajj GA, Schofield JT, Linfield RP, Hardy KR (1997) Observing Earth's atmosphere with radio occultation measurements using Global Positioning System. J Geophys Res 19(D19):23,429-23,465 
Marquardt C, Schöllhammer K, Beyerle G, Schmidt T, Wickert J, Reigber C (2003) Validation and data quality of CHAMP radio occultation data. In: Reigber C, Lühr H, Schwintzer P (eds) First CHAMP mission results for gravity, magnetic and atmospheric studies, Springer-Verlag, Berlin, pp 384-396

Melbourne WG, Davis ES, Duncan CB, Hajj GA, Hardy KR, Kursinski ER, Meehan TK, Young LE, Yunck TP (1994) The application of spaceborne GPS to atmospheric limb sounding and global change monitoring. JPL Publication 94-18, Jet Propulsion Laboratory, Pasadena, CA, USA

Reigber C, Lühr H, Schwintzer P, Wickert J (2004) Earth Observation with CHAMP: Results from Three Years in Orbit. Springer-Verlag, Berlin Heidelberg New York

Rocken C, Anthes R, Exner M, Hunt D, Sokolovskiy S, Ware R, Gorbunov M, Schreiner W, Feng D, Herman B, Kuo YH, Zou X (1997) Analysis and validation of GPS/MET data in the neutral atmosphere. J Geophys Res 102(D25):29,849-29,866

Sokolovskiy SV (2001) Tracking tropospheric radio occultation signals from low Earth orbit. Radio Sci 36(3):483-498

Vaisala (1989) Upper air systems: RS 80 radiosondes. Tech. rep., Vaisala GmbH, Hamburg

Ward P (1996) Understanding GPS: Principles and applications (edited by E. D. Kaplan), Artech House, Boston, London, chap Satellite signal acquisition and tracking

Wickert J, Reigber C, Beyerle G, König R, Marquardt C, Schmidt T, Grunwaldt L, Galas R, Meehan TK, Melbourne WG, Hocke K (2001) Atmosphere sounding by GPS radio occultation: First results from CHAMP. Geophys Res Lett 28(17):3263-3266

Wickert J, Schmidt T, Beyerle G, König R, Reigber C, Jakowski N (2004) The radio occultation experiment aboard CHAMP: Operational data processing and validation of atmospheric parameters. J Meteorol Soc Jpn 82(1B):381395 